\begin{tabular}{ccc}
\hline Sournals & $\begin{array}{c}\text { INTERNATIONAL JOURNAL OF } \\
\text { ORGANIZATIONAL LEADERSHIP }\end{array}$ & $\begin{array}{c}\text { INDUSTRIAL } \\
\text { MANAGEMENT } \\
\text { INSTITUTE }\end{array}$ \\
\hline \hline
\end{tabular}

\title{
A new Integration Model to Evaluate Strategic Performance of Supply Chain
}

\author{
Gholamreza Gholampour *1, Abdul Rahman Bin Abdul Rahim \\ ${ }^{1} \mathrm{PhD}$ candidate of Industrial Engineering, Department of industrial engineering, University Technology \\ ${ }^{2}$ Department of industrial engineering, University Technology Malaysia
}

\begin{abstract}
Keywords:

Supply Chain Management, Strategic Performance, IT, Organizational Learning, SEM

Correspondence:

Gholamreza1969@yahoo.com

Nowadays, Supply Chain Management (SCM) is one of the most important and complex issues for automakers in the world. The main objectives of this research were to investigate the factors that predict strategic performance of supply chain by doing quantitative research at Iran Khodro Company (IKCO) in Iran. Based on supply chain theories, strategic performance of supply chain was predicted by Information Technology (IT), Organizational Learning $(\mathrm{OL})$, and Product Innovation (PRI) in our research at the first time in an automotive company. Stratified random sampling was used to determine the sample size. Accordingly, 250 questionnaires were distributed among experts and supply chain specialists at IKCO. According to Supplying Automotive Parts Company (SPSC) variable as the main dependent variable, Path Analysis (PA) technique was used to explore casual relationships among variables using multiple regression analysis in SPSS. The Confirmatory Factor Analysis (CFA) was utilized based on Maximum Likelihood (ML) analysis of normality, outliers, composite reliability, and validity to test hypotheses by using AMOS. PA, measurement model, and structural model were analyzed in order to examine the conceptual model. The results from multiple regression, path analysis, and Structural Equation Modeling (SEM) were same. Thus, all hypotheses were supported by SPSS and SEM analyses. The findings of the study are discussed in detail.
\end{abstract}

(C)AIMI Journals

\section{Introduction}

Since the 1980s, manufacturing firms have developed Supply Chain (SC) to minimize load managements and production costs (Miles \& Snow, 2007). Supply Chain Management 
(SCM) consists of approaches and strategies to collect and integrate suppliers, producers, and all external actors to enhance organizational performance in the long term. Finally, SC is an integration set based on a business model used by high-performance managers (Cooper \& Kleinschmit, 2007). Supply chain management is one of the most important issues in industries, especially in automotive industries. Complexity of the supply chain due to complexity of automotive components and technology caused the automotive companies to find ways to improve and promote performance (Pires \& Neto, 2008). Therefore, automotive industries have contributed to value chain creation in supply chain. They have faced some challenges such as limit pricing, on-time delivery, quality, customer services, environmental subjects, product life cycle, new-product development, time to market, production costs, and chains relationships in competitive atmosphere. Some automakers are encountered with not having clearly defined mission, vision, and available long-term goals. In addition, having unclear information about the market atmosphere, competitors, and on time decision-making leads firms to poor decision making. In brief, this study aims to provide vital instruments to access high strategic performance goals. The next section of the article elaborates on SC of IKCO.

\section{Supply Chain of IKCO at a Glance}

In IKCO, according to its monthly, annual, and biannual plans, the weekly plan is prepared and ordered to SAPCO as SCM of IKCO for supplying parts to production line in sets. As it can be seen in Figure 1, the orders are done by ORACLE and KANBAN systems. IKCO and SAPCO automaker companies are linked by ORACLE, which orders issue to the suppliers by ORACLE software via SAPCO. This order for suppliers is noted and KANBAN system in SAPCO orders the suppliers the time, date, and number of items that must be delivered to IKCO's warehouses. The main suppliers to see the inventory of parts in IKCO' warehouse have username and ORACLE system-generated password.

A few years ago, SAP (business software like ERP) was utilized at IKCO to integrate all chains; nevertheless, it is still used at IKCO. SAPCO aims to develop information technology (IT) infrastructure using existing functionalities of SAP at IKCO and to develop it across the local and Completely Knocked Down (CKD) SCM. However, IKCO was encountered with some challenges in the field of strategic performance management across the SC. 


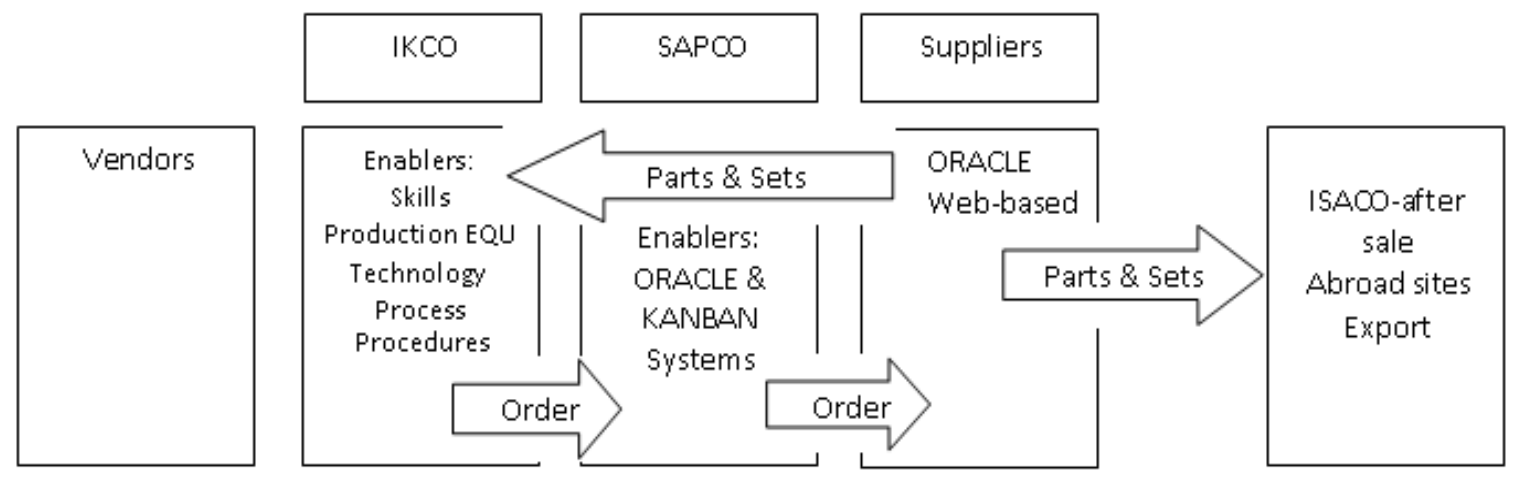

Figure1. The supply chain schematic of IKCO

\section{Strategic Performance of Supply Chain}

A number of studies conducted to date have emphasized on factors associated with new product development (NPD). Many investigations linked new product to strategic performance management (Molina-Castillo \& Munuera-Alemán, 2009) as one dimension of it. One of the most important themes in strategic performance management is to measure firm performance in the new product market domain. In fact, NPD performance indicators concentrate on measurement of the market response of the new products in different time durations and life cycles. About 25 per cent of first life cycle of each product is related to short term and 75 per cent of it is related to long term. SCM looks for convergence of inter and intra-organizations' operational and strategic capabilities as a unified organization (Pillai \& Min, 2010; Pires \& Neto, 2008). In addition, they seek to synchronize all relevant activities among chains. It is however difficult to synchronize and converge activities because the chains are independent and need a new link. Therefore, it is important to understand processes and instruments that link them together.

According to Andersen (2001), there are two main approaches for strategic decisions including centralized and decentralized. Whereas, decentralized strategic decision making involve all departments of firms, IT has the effective role to disperse decisions among departments. Speed, quality, accuracy, and reduction of transaction costs are outcomes of IT (Huber, 1990). Management Information System (MIS), as one of the outcomes of IT, includes Transaction Processing System (TPS), Decisions Support system (DSS), and Executive Information System (EIS). Given bidirectional flow of information from down to up and up to down, TPS covers operational level such as line production, warehouses, and quality procedures while DSS covers middle manager level and EIS covers top manager 
level. Strategic decisions are escalated to the executive level by information of MIS, TPS, and DSS that are flowing through an organization. Therefore, it can be argued that IT has positive effect on strategic performance (Anderson, 2001).

In this study, some indices were surveyed to measure dimensions of strategic performance, namely vision, mission, long-term goals, competitors' information for NPD, and making just in time strategic decision for NPD. One of the most important issues at automotive industries is to plan strategically in the field of NPD, which should be considered at long-term goals. Deming (1992) utilized profound knowledge to explain necessary knowledge for managers and workers in order to plan and run systematically. These activities are utilized to enhance capabilities and skills. He places emphasis on psychology to understand people's needs. Learning process takes place via acquiring knowledge and information which is related to improving quality, processes, procedures, and developing new products.

Knowledge and information are similar to blood in vessels of livings which need to flow across firms' body. Occupational knowledge improves work quality, in particular in technical jobs. Rapid technological changes prove the significance of knowledge sharing across the supply chain. Therefore, focal firms in industrial districts should share information and knowledge among supply chains to develop learning. More than two decades, we have witnessed computerized information flow by technological development, which has been used a wide variety of tools for documenting transactions, improving decision making, and speeding up information flow. Therefore, firms can improve their inter-organizational relationships and interactions by learning and using special software systems (e.g., SAP, ORACLE, and ERP) and market-oriented systems (Vijayasarathy, 2010).

\section{New Product Development (NPD)}

Around 20 years ago, automotive companies and suppliers have increased product innovation. Indeed, they rapidly move toward the new products to fill the perceived gap in the markets. Automotive companies have encountered with some difficulties in evaluating new products' innovation, repetition, reliability, nature, and profitability, and which departments of research and development are faced with them (Beaume, Maniak, \& Midler, 2009).

Customer firms can take advantage of the suppliers who are involved in NPD activities such as product quality, cost, innovativeness, time-to-market rather than working 
independently. Additionally, conserving resources, sharing risks, and gaining new competencies can help these firms move faster into new markets (Koufteros, Cheng, \& Lai 2007; Takeishi 2001; Wagner, 2009).

One of the most important issues in strategic performance management systems is to measure firm performance in new product domain. In fact, performance indicators of NPD include the number of new products in different time series, time-to-market, pricing, and long term goals to develop new products. In this study, the positive relationship between mission quality and financial performance was highlighted. It should be pointed out that mission components consist of products, main technology, location, financial objectives, and organization philosophy (David, 1989). The key chains such as key suppliers and customers should be involved in the field of vision, mission, long term goals, and NPD by main firms as leaders. Companies are required to develop new products in order to consider needs of market and customers (Rahim \& Baksh, 2003).

\section{Organizational Learning (OL)}

Drucker (1993) argues that knowledge-based employees are vital assets of firms and key components of a successful organization. Employees' skills are attained via training and experience. In fact, it is the degree of learning that employees can do their functions accurately and in time. Mohnen and Roller (2005) emphasized that employees'skills are an important factor in driving innovation. In their study, they proved that lack of adequate skills in many industries was the most important barrier for innovation. In fact, in learning organizations, OL is processed systematically. Learning organizations are adjusted to reflect the new knowledge toward long term goals. They focus on enhancing the learning of skills and creating, acquiring, organizing, and sharing knowledge (Gravin, 1994). Therefore, OL is a transformational process whereby knowledge is updated to enhance skills and innovation capabilities.

\section{The Conceptual Framework of the Study}

The conceptual framework of the theories and concepts that are relevant to the study is depicted in Figure 2. 


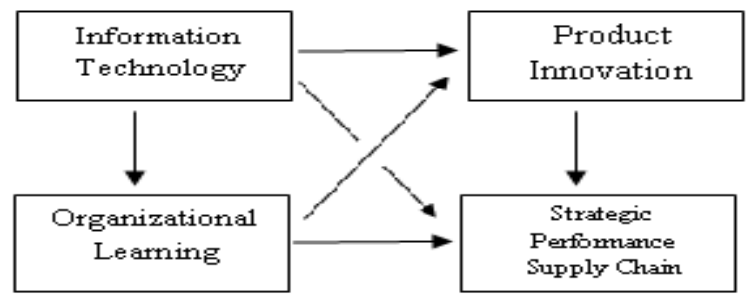

Figure2. Conceptual framework of the research

Sanders and Premus (2002) conducted an empirical research to investigate the direct effect of technology on supply chain performance. They reported that organizations could achieve operational benefits such as decreasing the cost and cycle time of functions using IT across SCM.

\section{Research Hypotheses}

$H_{1}$ : IT has positive effect on SPSC.

Generally, NPD is one of the strategic outcomes of organizations. Successful organizations involve key suppliers and vendors to develop new product (Marmeir, Gourc, \& Laarz, 2013; Shen \&Yu, 2009). Findings of majority of studies to date show that NPD strategy should be the focal point of organizations (Crawford, 1980; Day, 1975; Frambach, Prabhu, \& Verhallen, 2003). Some studies have emphasized on factors associated with NPD. Many of these investigations linked new product to strategic performance (Molina, Castillo, \& Munuera Aleman, 2009). In fact, one of the most important themes in strategic performance is to measure firm performance in new product domain. Hence, the second hypothesis can be postulated as:

\section{$\mathrm{H}_{2}$ : PRI has positive effect on SPSC.}

Time series of new product such as the number of new product in certain period is one of the dimensions of strategic performance measurement. Cooper and Kleinschmidt (2007) introduced some critical factors such as skills, organizational structures, relationship quality, and OL to develop new product. Based on the literature mentioned above, the following third hypothesis was formulated as:

$\mathrm{H}_{3}$ : OL has positive effect on SPSC.

Using IT tools helps improve NPD outcomes (Durmuşoğlu \& Barczak, 2011). O’Mahony, Padmore, and Suh (2003) found that more than 90 per cent of senior managers believed that 
IT enables innovation at all organizational layers. Durmuşoğlu and Barczak (2011) observed that the use of decision support system technologies as one of IT tools improves NPD. Song, Berends, Van der Bij, and Weggeman (2007) surveyed the use of IT during NPD activities among relevant departments such as planning, engineering, and production; they observed that applying IT facilitates NPD. Thus, the fourth hypothesis was formulated as:

\section{$\mathrm{H}_{4}$ : IT has positive effect on PRI.}

Attaining processes and information interaction between sections of organizations are supported by IT (Ruiz-Mercader, Meroño-Cerdan, \& Sabater-Sánchez, 2006) which requires appropriate environment to share knowledge (Davenport, DeLong, \& Beers, 1998) and appropriate human capital (Lee \& Choi, 2003). Empirical research has shown that there is positive relationship between IT and OL. IT facilitates OL through knowledge and information sharing (Robey, Boudreau, \& Rose, 2000).

Based on studies to date, the fifth and sixth hypotheses were formulated as:

$H_{5}$ : IT has positive effect on OL.

$H_{6}$ : OL has positive effect on PRI.

\section{Method}

The literature reveals many investigations which have been conducted to inquire into different aspects of SCM (Niemi, Pekkanen, \& Huiskonen, 2007). This research aimed to identify the factors that predict strategic performance of supply chain. This is an applied research in purpose and a descriptive survey in the way the data were collected. We, in this study, used quantitative approach to evaluate strategic performance of supply chain. The participants included experts and mangers of IKCO in Iran. Sampling was done by using the stratified random sampling method proportionate to the sample size. A questionnaire was used for data collection. This questionnaire included four latent variables with eleven items which were used to test the research model (Olugu, Wong, \& Shaharoun, 2010) and 11 statements that measured respondents' frequency of their use by means of five-point Likertscale questions, namely (1) strongly agree to (5) strongly disagree. In fact, a pilot test was administered to improve the items and finalize the questionnaire. Some scholars in the field confirmed the face validity of the questionnaire. Pilot group completed the questionnaire in order to measure its reliability. Fifty questionnaires for pilot study and 250 questionnaires for main research were distributed among the respondents at IKCO. From 250 of IKCO' 
respondents, approximately 234 (93.6\%) returned which just eight (3.2\%) of them were rejected due to being incomplete.

\section{Results}

In this research, the Cronbach's alpha was used to assess the internal consistency of the questionnaire. Based on McMillan and Schumacher (2009) approach, Cronbach's alpha values between 0.7 and 0.9 are usually acceptable and imply a high reliability and value of alpha below 0.7 is unacceptable and demonstrates weak reliability. The overall value of $\alpha$ was 0.9 which was greater than all $\alpha$ values of items. Based on the results of data analysis, all $\alpha$ values in the pilot test and main research were acceptable. Using SEM to examine the model, Mahalanobis distance was evaluated to identify outliers. The data of Mahalanobis distance revealed that nine cases of IKCO were outliers. At least one of $p_{1}$ or $p_{2}$ values was more than 0.05. In addition, the values of all theses nine cases were less than 3.5 which is an appropriate criterion for large sample size but not for being outlier (Abareshi \& Hosseini, 2012). We, also, used the PA in order to create a hierarchical model and explore casual relations among variables.

\section{The Path Analysis of SPSC Model}

According to research theories, through using multi-regression SPSC variable was chosen as dependent and others variables such as IT, OL, and PRI were regarded as independent variables. Based on PA rule, by considering values of $\beta$ for all independent variables, the variable with the highest value of $\beta$ is selected as a new dependent variable. Of course, if this variable has critical ratio more than +1.96 or less than -1.96 , which is significant in probability level of 0.05 , remains in model and if it does not have it, it must be deleted. Figure 3 presents the PA of SPSC model at IKCO.

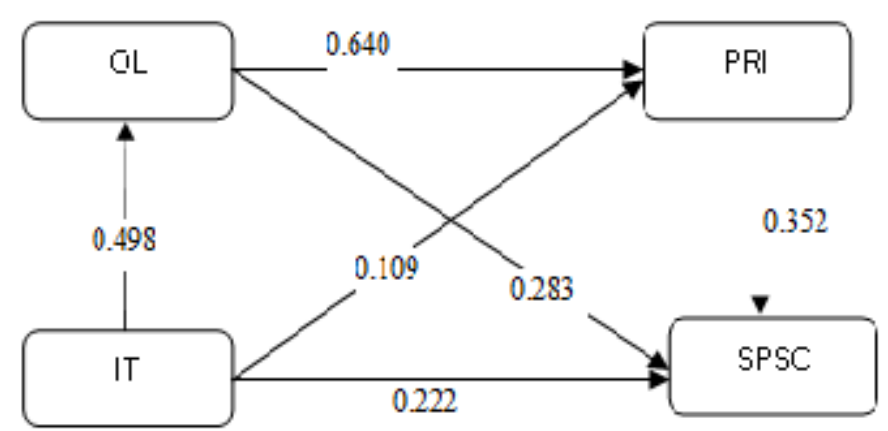

Figure3.The path analysis of SPSC model at IKCO 


\section{The First-order CFA of SPSC Model}

Measurement model was employed to ensure the reliability and validity of SPSC's constructs and items. As Figure 4 shows, SPSC model includes SPSC, PRI, OL, and IT. Approximately, the values of multiple squared correlations for all items were more than 0.5 , except PRI, which indicated appropriateness of items in constructs.

The correlations between constructs were less than 0.7 which were acceptable to examine CFA model. The fit indices of SPSC model and Root Mean Square Error of Approximation (RMSEA) implied statistical measures of goodness-of-fit.

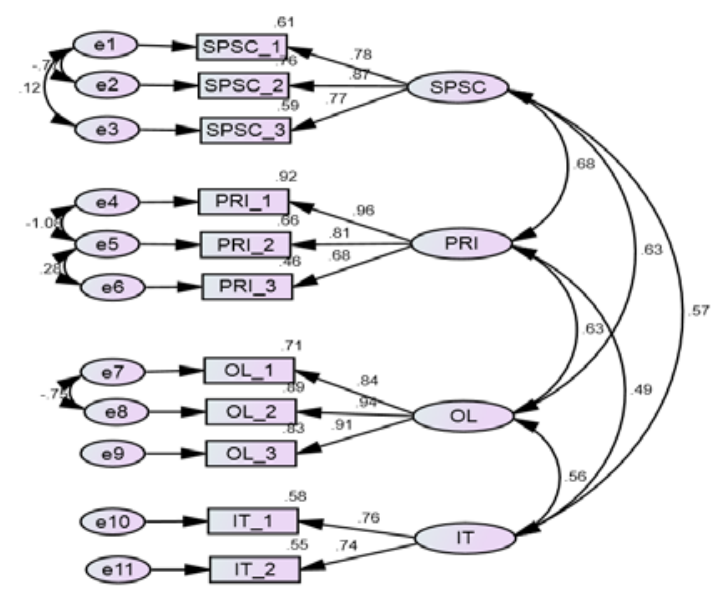

Figure4. Measurement model of SPSC model at IKCO

\section{The Structural Model-CFA}

The path diagram construction of SPSC model including observed, latent, residual, and error variables was illustrated in Figure 5. The CFA was utilized based on ML estimation (Abareshi \& Hosseini, 2012). Figure 5 reveals that all indices showed high goodness-of-fit.

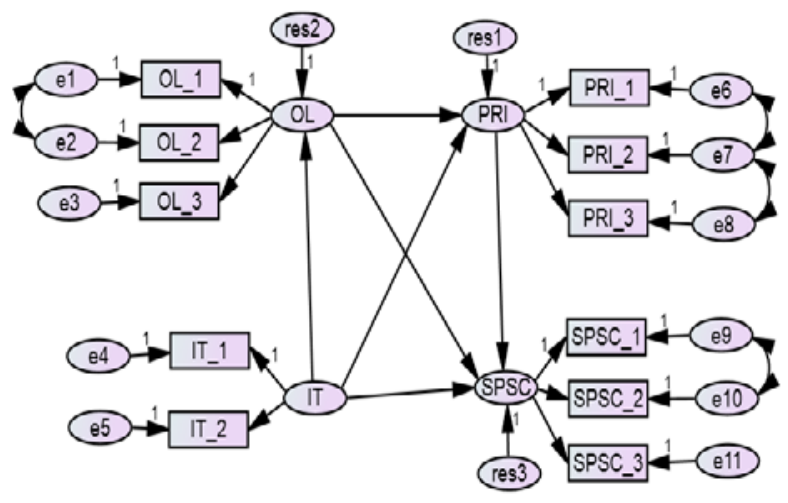

Figure 5. CFA of structural model of SPSC model at IKCO 


\section{Discriminant and Convergent Validity}

Both convergent and discriminant validities were assessed by CFA based on Baker, McFall, and Shoham (2009). The ML estimation used to fit model by estimating fit indices. Convergent validity indicates the agreement between the scales when under appropriate conditions, the resulting CFA parameter estimates the best model with regard to goodness-offit and all factor loadings are highly acceptable (Bentler \& Bonett, 1980). Discriminant validity was introduced by Campbell and Fiske (1959) to evaluate validity that is the extent to which the scales represent a latent variable to investigate whether they are relevant or irrelevant. It is very important when scales are highly correlated with other scales. Hair, Tatham, Anderson, and Black (2010) emphasized that the value of 0.3 for factor loadings is significant, 0.4 is more important and 0.5 or more is very significant. The factor loadings of SPSC model were ranged from 0.67 to 0.96 which were very significant.

Surveying squared multiple correlation shows that values related to dependent variables is equivalent in regression analysis. It means that the default model explains 31.4 per cent of covariance of OL, 41.7 per cent of covariance of PRI, and 55.1 per cent of covariance of strategic performance. Squared multiple correlation of observed variables were more than 0.5 , which indicates appropriate latent variable scales of measurement. Based on the results of the data analysis the discriminant validity was established.

\section{Multicollinearity}

When model fitting is surveyed, multicollinearity of variables should be assessed in order to show that there is no high inter-correlation among independent variables. In fact, multicollinearity problem occurs when an independent variable has high correlation with another independent variable. Multicollinearity implies to an unacceptable high level of correlation among independent variables. Therefore, it may be argued that two independent variables are equal to predict the dependent variables. It means that one of them should be omitted from the model. If the inter-correlation of independent variables is above 0.8 , there is multicollinearity problem (Thompson \& Walker, 1998). A high degree of multicollinearity leads to wrong regression coefficients in outcome (Hair, Tatham, Anderson, \& Black, 2010). Using SPSS, multicollinearity of SPSC scales were evaluated, which the values of VIF for all scales were less than 5 and tolerance values were more than 0.2 , which implied acceptable condition for multicollinearity test (Bryman \& Cramer, 2011). 


\section{Discussion}

Based on ML estimation and CFA evaluation, hypotheses testing were performed. Many prior studies have explored that IT is an enabler to support OL (Davenport, DeLong, \& Beers, 1998; Stein \& Zwass, 1995; Walsh \& Ungson, 1991, to name but a few) and a few studies emphasized that it is a disabler to support OL (Robey, Boudreau, \& Rose, 2000). Gill (1995) emphasized that IT is a disabler to support OL, while this study revealed that IT has positive effect on OL. Using IT tools helps improve NPD outcomes (Durmuşoğlu \& Barczak, 2011). It is observed that more than 90 per cent of senior managers believed that IT enables innovation at all organizational layers (O’ Mahony, Padmore, \& Suh, 2003). Durmuşoğlu and Barczak (2011) examined the use of decision support systems as one of IT tools for improving NPD. Song, Berends, Van der Bij, and Weggeman (2007) surveyed the use of IT during NPD activities among relevant departments such as planning, engineering, and production which facilitate NPD. Therefore, the findings of this study confirmed that IT has positive effect on product innovation. So, it can be argued that IT has positive effect on strategic performance.

OL improves human capital skills to develop new product (Hsu \& Fang, 2009). In this study, based on path analysis technique and SEM, it was found that OL has positive effect on product innovation. Therefore, this study proved that OL has positive impact on strategic performance of supply chain. Some researches identified that NPD strategies should be focal activities in organizations (Crawford, 1980; Frambach, Prabhu, \& Verhallen, 2003). The data analysis also revealed PRI has positive effect on strategic performance of supply chain.

This study has contributions to supply chain management at automotive industries. especially in Iran. After making SPSC model by path analysis and examination of them the status of their constructs, namely IT, OL, PRI, and SPSC were evaluated at IKCO by using survey. Using this model, managers and experts are able to assess the strengths and weaknesses of their organizations and develop appropriate strategies to improve their weaknesses. They should focus on IT as the main infrastructure to link all chains of SC, OL as enabler across supply chain, NPD via involving key suppliers and customers, and finally strategic performance of supply chain to access key results of performance. This study configured SPSC model under an empirical research in automotive industry using quantitative research. The basis of SPSC model is to develop strategic performance of supply chain by IT, OL, and product innovation. Figure 6, presents general categorized constructs of SPSC model. Also, Table 1 summarizes the improvement domains at IKCO. 

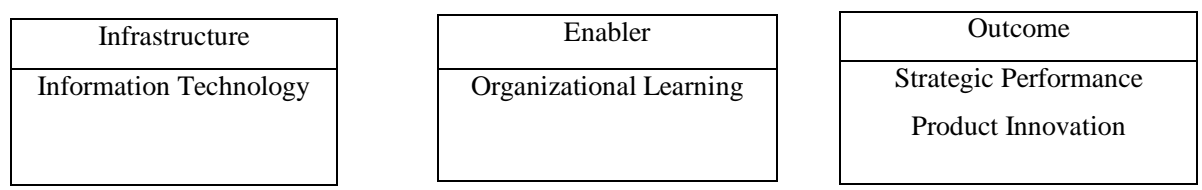

Figure 6. General categorized constructs of SPSC model

Table 1

Improvement Domains at IKCO

\begin{tabular}{ll}
\hline Improvement Domain & \multicolumn{1}{c}{ Description } \\
\hline IT & To develop SAP across SAPCO and suppliers \\
OL & To develop learning suppliers based on audited needs \\
PRI & To research market needs and produce product around less than 3500USD \\
SPSC & To enhance IKCO by selling shares of suppliers site and make decision on time \\
& to develop new products
\end{tabular}

Table 1 indicates the improvement domains of IKCO which managers need to focus on them. IT as an infrastructure of SC should be developed to cover all chains in order to access information flow effectively. OL is required to be developed via knowledge sharing, training, and benchmarking. Key suppliers need to be involved to develop new products. The long term goals should cover new products plans. In sum, it is imperative to stress that one of the most important plans in strategic issues is to develop new product based on customer needs and market information.

\section{Conclusion}

The SPSC model was configured under a survey research in automotive industries using path analysis and CFA. The basis of SPSC model is to develop strategic performance of supply chain by IT, OL, and PRI. According to key findings, all hypotheses were supported at IKCO using multi-regression and structural equation modeling. Discriminant and convergent validity indicated appropriate validity of model. All values of incremental and absolute measures confirmed the measures of goodness-of-fit model. To sum up, SPSC was predicted by IT, OL, and PRI. Therefore, IKCO should plan to develop IT, OL, and PRI in order to enhance strategic performance of supply chain.

\section{References}

Abareshi, A., \& Hosseini,Y. (2012). Strauctural equation modeling. Tehran: Jameshenasan Publication.

Andersen, T. J. (2001). Information technology, strategic decision making approaches and organizational performance in different industrial settings. Journal of Strategic Information Systems, 10(2), 101-119. 
Baker, T. B., McFall, R. M., \& Shoham, V. (2009). Current status and future prospects of clinical psychology: Toward a scientifically principled approach to mental and behavioral health care. Psychological Science in the Public Interest, 9(2), 67-103.

Beaume, R., Maniak, R., \& Midler, C. (2009). Crossing innovation and product projects management: A comparative analysis in the automotive industry. International Journal of Project Management, 27(2), 166-174.

Bentler, P. M., \& Bonett, D. G. (1980). Significance tests and goodness of fit in the analysis of covariance structures. Psychological Bulletin, 88(3), 588-606.

Bryman, A., \& Cramer, D. (2011). Quantitative data analysis with IBM SPSS 17, 18 and 19: A guide for social scientists. London: Routledge.

Campbell, D. T., \& Fiske, D. W. (1959). Convergent and discriminant validation by the multitrait-multimethod matrix. Psychological Bulletin, 56(2), 81-105.

Cooper, R. G., \& Kleinschmidt, E. J. (2007). Winning businesses in product development: The critical success factors. Research Technology Management, 39(4),18-29.

Crawford, C. M. (1980). Defining the charter for product innovation. Sloan Management Review, 22(1), 3-12.

Davenport, T. H., DeLong, D. W., \& Beers, M. C. (1998). Successful knowledge management projects. Sloan Management Review, 39(2),43-57.

David, F. R. (1989). How companies define their mission. Long Range Planning, 22(1), 90-97.

Day, G. S. (1975). A strategic perspective on product planning. Journal of Contemporary Business, 4(2), 1-34.

Deming, W. E. (1992). A system of profound knowledge. Konexvill, TN: SPSS Press.

Drucker, P. F. (1993). Post-capitalist society. New York, NY: Harper Business.

Durmuşoğlu, S. S., \& Barczak, G. (2011). The use of information technology tools in new product development phases: Analysis of effects on new product innovativeness, quality, and market performance. Industrial Marketing Management, 40(2), 321-330.

Frambach, R. T., Prabhu, J., \& Verhallen, T. M. (2003). The influence of business strategy on new product activity: The role of market orientation. International Journal of Research in Marketing, 20(4), 377-397.

Garvin, D. A. (1994). Building a learning organization. Business Credit-New York, 96(1), 19-28.

Gill, T. G. (1995). High-tech hidebound: Case studies of information technologies that inhibited organizational learning. Accounting, Management and Information Technologies, 5(1), 41-60.

Hair, J. F., , Tatham, R. L., Anderson, R. E., \& Black, W. C. (2010). Multivariate data analysis (Vol. 7). Upper Saddle River, NJ: Prentice Hall.

Hsu, Y. H., \& Fang, W. (2009). Intellectual capital and new product development performance: The mediating role of organizational learning capability. Technological Forecasting and Social Change, 76(5), 664-677.

Huber, G. P. (1990). A theory of the effects of advanced information technologies on organizational design, intelligence, and decision making. Academy of Management Review, 15(1), 47-71.

Koufteros, X. A., Cheng, T., \& Lai, K. H. (2007). "Black-box" and "gray-box" supplier integration in product development: Antecedents, consequences and the moderating role of firm size. Journal of Operations Management, 25(4), 847-870.

Lee, H., \& Choi, B. (2003). Knowledge management enablers, processes, and organizational performance: An integrative view and empirical examination. Journal of Management Information Systems, 20(1), 179-228.

Marmier, F., Gourc, D., \& Laarz, F. (2013). A risk oriented model to assess strategic decisions in new product development projects. Decision Support Systems, 56(5), 74-82.

McMillan, J. H., \& Schumacher, S. (2009). Research in education: Evidence-based inquiry (7 ${ }^{\text {th }}$ ed.). Upper Saddle River, NJ: Pearson Education.

Miles, R. E., \& Snow, C. C. (2007). Organization theory and supply chain management: An evolving research perspective. Journal of Operations Management, 25(2), 459-463.

Mohnen, P., \& Roller, L. H. (2005). Complementarities in innovation policy. European Economic Review, 49(6), 14311450 .

Molina-Castillo, F. J., \& Munuera-Alemán, J. L. (2009). New product performance indicators: Time horizon and importance attributed by managers. Technovation, 29(10), 714-724.

Niemi, P., Pekkanen, P., \& Huiskonen, J. (2007). Improving the impact of quantitative analysis on supply chain policy making. International Journal of Production Economics, 108(1), 165-175. 
O'Mahony, R., Padmore, L., \& Suh, B. (2003). The Innovator's Advantage:Using innovation and technology to improve business performance. London: Accenture.

Olugu, E. U., Wong, K. Y., \& Shaharoun, A. M. (2010). Development of key performance measures for the automobile green supply chain. Resources, Conservation and Recycling,55(6), 567-579.

Pillai, K. G., \& Min, S. (2010). A firm's capability to calibrate supply chain knowledge. Industrial Marketing Management, 39(8),1365-1375.

Pires, R. I. S., \& Neto, M. S. (2008). New configurations in supply chains: The case of a condominium in Brazil's automotive industry. Supply Chain Management: An International Journal, 13(4), 328-334.

Rahim, A. R. A., \& Baksh, M. S. N. (2003). Case study method for new product development in engineer-to-order organizations. Work Study, 52(1), 25-36.

Robey, D., Boudreau, M. C., \& Rose, G. M. (2000). Information technology and organizational learning: A review and assessment of research. Accounting, Management \& Information Technologies, 10(2), 125-155.

Ruiz-Mercader, J., Meroño-Cerdan, A. L., \& Sabater-Sánchez, R. (2006). Information technology and learning: Their relationship and impact on organisational performance in small businesses. International Journal of Information Management, 26(1), 16-29.

Sanders, N. R., \& Premus, R. (2002). IT applications in supply chain organizations: A link between competitive priorities and organizational benefits. Journal of Business Logestics, 23(1), 65-83.

Shen, C. Y., \& Yu, K. T. (2009). Enhancing the efficacy of supplier selection decision-making on the initial stage of new product development: A hybrid fuzzy approach considering the strategic and operational factors simultaneously. Expert Systems with Applications, 36(8), 11271-11281.

Song, M., Berends, H., Van der Bij, H., \& Weggeman, M. (2007). The effect of IT and co-location on knowledge dissemination. Journal of Product Innovation Management, 24(1), 52-68.

Stein, E. W., \& Zwass, V. (1995). Actualizing organizational memory with information systems. Information Systems Research, 6(2), 85-117.

Thompson, C. B., \& Walker, B. L. (1998). Basics of research (part 12): Qualitative research. Air Medical Journal, 17(2), 65-70.

Vijayasarathy, L. R. (2010). An investigation of moderators of the link between technology use in the supply chain and supply chain performance. Information \& Management, 47(7), 364-371.

Wagner, S. M. (2009). Getting innovation from suppliers. Research-Technology Management, 52(1), 8-9.

Walsh, J. P., \& Ungson, G. R. (1991). Organizational memory. Academy of Management Review, 16(1), 57-91. 